\title{
Analysis of Regional Hemodynamic Regulation in Response to Scald Injury
}

\author{
Paul A. Taheri, * Howard L. Lippton, * ${ }^{*}$ Seth D. Force, * Ernest W. Franklin, * \\ Albert L. Hyman, ${ }^{\star 5}$ Lewis M. Flint, ${ }^{\star}$ and John J. Ferrara* \\ ${ }^{*}$ Department of Surgery, Tulane University School of Medicine, ${ }^{\ddagger}$ Departments of Internal Medicine and Pharmacology, Louisiana State \\ University School of Medicine, and ${ }^{\S}$ Departments of Pharmacology and Internal Medicine, Tulane University School of Medicine, \\ New Orleans, Louisiana 70112
}

\begin{abstract}
Ultrasonic probes were placed around dog femoral arteries to record blood flow. Hind paw scalding with boiling water ( $5 \mathrm{~s})$ caused a marked increase in ipsilateral femoral blood flow that persisted for the 2-h observation period. Contralateral femoral blood flow and systemic and pulmonary vascular resistances were unchanged. Compared to scald only animals, methysergide pretreatment diminished and shortened the femoral vasodilator response to scald $(109 \pm 14 \mathrm{vs} 243 \pm 27 \mathrm{ml} / \mathrm{min}$ at $5 \mathrm{~min}$; $59 \pm 14$ vs $191 \pm 31 \mathrm{ml} / \mathrm{min}$ at $2 \mathrm{~h}$ ). Pretreatment with ritanserin, BW A1433U83, atropine, ICI 118551, diphenhydramine, ranitidine, meclofenamate, $L$-nitro-arginine methyl ester, 3-amino-1,2,4-triazine, and $U$ 37883A had no effect on the increased femoral blood flow response to scald, suggesting this vasodilator response is not dependent upon activation of serotonergic $_{2}$, adenosine ${ }_{\mathrm{A1}}$, muscarinic, $\beta_{\mathbf{2}}$-adrenergic, histaminergic $_{1}$ or histaminergic ${ }_{2}$ receptors, on cyclooxygenase products, endothelium-derived relaxing factor derived from nitric oxide (NO) synthase III, NO derived from NO synthase II, or $K_{\text {ATP }}$ channels, respectively. Methysergide given after burn immediately reduced the augmented femoral blood flow to preburn levels, suggesting the vasodilator response to scald is mediated through continual activation of local serotonergic ${ }_{1}$-like receptors, which may be target site(s) for therapeutic interventions to influence burn-induced hemodynamic alterations. (J. Clin. Invest. 1994. 93:147-154.) Key words: burns • vasodilation • serotonin receptors $\bullet$ vascular resistance $\bullet$ ultrasonic blood flow probes
\end{abstract}

\section{Introduction}

In patients with large body surface area (BSA) ${ }^{1}$ burns, both cardiac output and blood flow to the injured area are increased for several days $(1,2)$. Animal studies have also documented a

Address correspondence to John J. Ferrara, M.D., Department of Surgery, Tulane University School of Medicine, 1430 Tulane Avenue, New Orleans, LA 70112.

Received for publication 15 March 1993 and in revised form 16 August 1993.

1. Abbreviations used in this paper: 3-ATINE, 3-amino-1,2,4-triazine; BSA, body surface area; CATM, 5-carboxamidotryptamine; CI, cardiac index; CNS, central nervous system; CO, cardiac output; EDRF, endothelium-derived relaxing factor; L-NAME, L-nitro-arginine methyl ester; MAP, mean arterial pressure; MET, methysergide; NOS, nitric oxide synthase; PAP, pulmonary artery pressure; PCWP, pulmonary capillary wedge pressure; RIT, ritanserin.

J. Clin. Invest.

(c) The American Society for Clinical Investigation, Inc.

0021-9738/94/01/0147/08 $\$ 2.00$

Volume 93, January 1994, 147-154 prolonged increase in blood flow to a large wound (3). However, acute alterations in blood flow to a burn site are poorly delineated. In guinea pigs, a large BSA burn produces an acute decrease in blood flow to the wound, likely caused by diminished cardiac output (4). A smaller BSA burn in rats causes only an increase in blood flow to the injured site, a response influenced by surface temperature and injury size (5). Mediation of this regional vasodilator response by potassium, prostaglandins, lactate, and activation of $\beta$-adrenoceptors (3, 6-9) has been suggested. Others consider heat-induced vasodilation a prime component of this response (5). The role of these vasodilatory mechanisms is unclear.

These experiments were designed to characterize the effect of a small BSA scald on systemic, pulmonary, and regional (burned and unburned sites) hemodynamics. The effects of blocking agents for known vasoactive receptors and potassium channels on burn-induced hemodynamic alterations were also investigated. These data indicate that in the absence of systemic or pulmonary hemodynamic effects, blood flow to the injured area acutely increased, and regional vascular resistance decreased. These responses were selectively inhibited by the serotonin receptor blocking agent, methysergide. Since ritanserin, a serotonin ${ }_{2}$ receptor blocking agent, had no effect on these alterations, the data suggest that continuous activation of

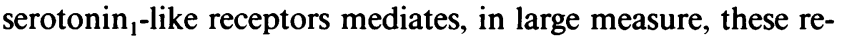
sponses.

\section{Methods}

Surgical protocol. Adult mongrel dogs weighing 20-35 kg were anesthetized with intravenous sodium pentobarbital $(25 \mathrm{mg} / \mathrm{kg}$ per $\mathrm{h})$ and placed on room air mechanical ventilation. Systemic mean arterial pressure (MAP, $\mathrm{mmHg}$ ) was measured through a cannulated brachial artery. Pulmonary artery pressure $(\mathrm{PAP}, \mathrm{mmHg}$ ) and pulmonary capillary wedge pressure ( $\mathrm{PCWP}, \mathrm{mmHg}$ ) were monitored by insertion of a balloon-tipped pulmonary artery catheter via internal jugular vein cutdown. Ringer's lactate solution ( $2-3 \mathrm{ml} / \mathrm{kg}$ per $\mathrm{h}$ ) was infused to maintain baseline MAP and PCWP.

An ultrasonic flow probe (Transonic Systems, Inc., Ithaca, NY) was placed around the ascending aorta via left thoracotomy in certain groups of dogs (designated later), to record cardiac output minus coronary artery flow ( $\mathrm{CO}$, liter/min); systemic vascular resistance $(\mathrm{mmHg} /$ liter per $\mathrm{min})$ was calculated. Cardiac index $(\mathrm{CI}$, liter $/ \mathrm{min}$ per $\mathrm{m}^{2}$ ) was calculated from canine nomograms. Isolation of a carotid artery was carried out in four animals to provide access for intracarotid injections.

Ultrasonic flow probes were placed around both femoral arteries to record femoral blood flow $(\mathrm{ml} / \mathrm{min})$, and these values were used to calculate femoral vascular resistance $(\mathrm{mmHg} / \mathrm{ml}$ per $\mathrm{min})$. In some dogs, a side branch of the femoral artery on the side to undergo an experimental manipulation was cannulated to provide access for intrafemoral injections. Dogs were randomly assigned to a protocol only after monitored hemodynamic parameters were stable for $30 \mathrm{~min}$.

Experimental groups. A sham treatment group $(n=4)$ underwent the surgical preparation as described above, and was then monitored 

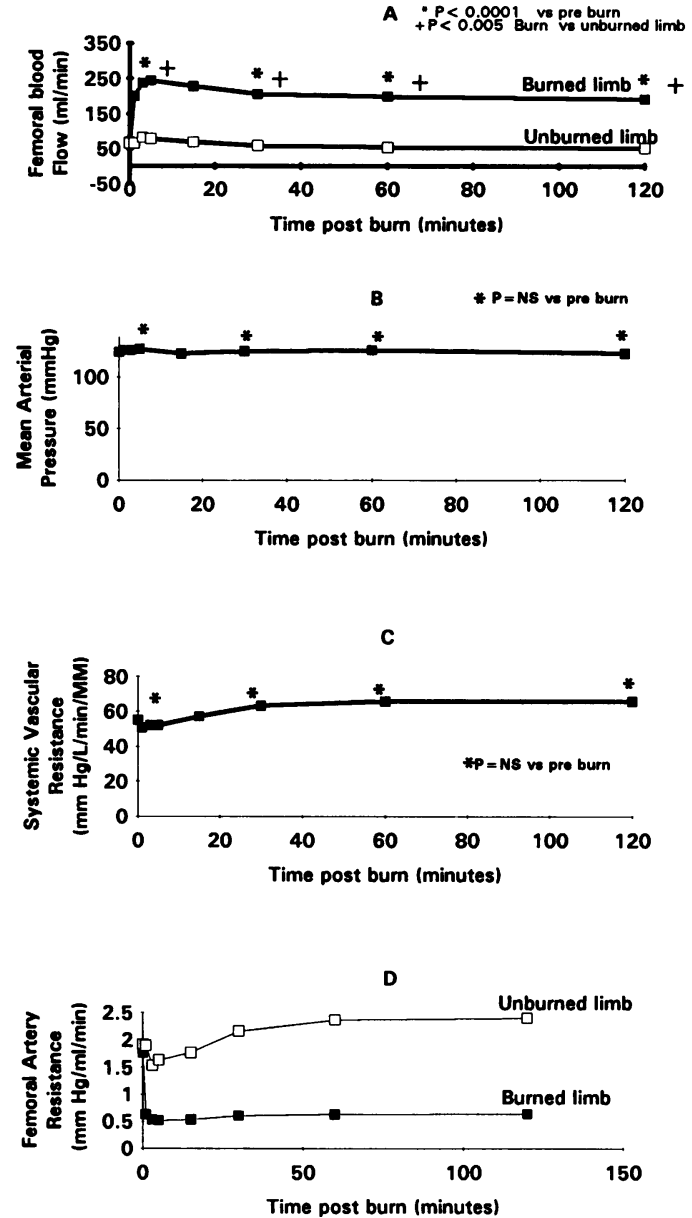

Figure 1. Effects of hind paw scald on regional and systemic hemodynamics. The threefold increase in femoral blood flow $(A)$ and decrease in femoral vascular resistance $(D)$ to the site of injury occurs without blood flow alterations to unburned tissues, systemic mean arterial pressure $(B)$, or systemic vascular resistance $(C)$.

for $2 \mathrm{~h}$ with no further intervention. Remaining animals were exposed to scald injury, immersion of one hind paw $(<3 \% \mathrm{BSA})$ into $100^{\circ} \mathrm{C}$ water for $5 \mathrm{~s}$, and hemodynamic parameters were monitored for $2 \mathrm{~h}$ thereafter. Since in scald only animals (controls, $n=9$ ), identical increases in hind limb blood flow and decreases in hind limb vascular resistance occurred regardless of which paw (right $[n=5]$ or left [ $n$ $=4]$ ) was injured, they were combined into one group. In subsequent groups of dogs, one of the following agents was intravenously infused 20 min before scalding, in a dose shown to adequately block the respective agonist agent response: methysergide $(0.1 \mathrm{mg} / \mathrm{kg}, n=7)$, ritanserin $(0.1 \mathrm{mg} / \mathrm{kg}, n=5)$, atropine $(1 \mathrm{mg} / \mathrm{kg}, n=4)$, ICI $118551(1$ $\mathrm{mg} / \mathrm{kg}, n=4)$, BW A1433U83 (7.5 mg/ $\mathrm{kg}, n=6)$, sodium meclofenamate $(2.5 \mathrm{mg} / \mathrm{kg}, n=4)$, diphenhydramine $(1 \mathrm{mg} / \mathrm{kg}, n=5)$, ranitidine ( $1 \mathrm{mg} / \mathrm{kg}, n=4)$; L-nitro-arginine methyl ester (L-NAME, 100 $\mathrm{mg} / \mathrm{kg}, n=7$ ), 3-amino-1,2,4-triazine (3-ATINE, $75 \mathrm{mg} / \mathrm{kg}, n=3$ ), or U $37883 \mathrm{~A}(2.5 \mathrm{mg} / \mathrm{kg}, n=4)$.

To further elucidate what was found to be a methysergide-sensitive femoral vasoactive response in animals pretreated with that agent, additional protocols were carried out. In separate groups of animals, methysergide was given no sooner than $30 \mathrm{~min}$ after scald: $(a)$ by peripheral intravenous injection $(0.1 \mathrm{mg} / \mathrm{kg}, n=4 ; 1.0 \mathrm{mg} / \mathrm{kg}, n=3)$ and $(b)$ by bolus injection directly into the femoral artery on the side of injury $(20 \mu \mathrm{g} / \mathrm{kg}, n=4)$. In another group $(n=4)$ of dogs, methysergide $(20 \mu \mathrm{g} / \mathrm{kg})$ was infused into the cranial circulation via one common carotid artery before scalding. Finally, to determine the specificity of the femoral vasoactive response to methysergide, random sequence intrafemoral artery injections of the following vasoconstrictor and vasodilator agents were performed in a group $(n=5)$ of unburned dogs before and after peripheral intravenous administration of methysergide $(0.1 \mathrm{mg} / \mathrm{kg})$ : methoxamine $(0.1 \mu \mathrm{g} / \mathrm{kg})$, nitroglycerin $(0.003 \mu \mathrm{g} / \mathrm{kg})$, verapamil $(0.001 \mu \mathrm{g} / \mathrm{kg})$, serotonin $(0.001 \mu \mathrm{g} / \mathrm{kg})$, 5-carboxamidotryptamine (CATM, $0.0001 \mu \mathrm{g} / \mathrm{kg}$ ).

Statistical analysis. Data are presented as means $( \pm 1 \mathrm{SE})$. Comparisons both within a given group and between groups were made using ANOVA. Whenever a significant $F$ ratio was reached, Fisher's PSLD test was applied to detect specific differences. Significance was accepted when $P<0.05$.

\section{Results}

Immediately after the scalding, there was a significant threefold increase in femoral artery blood flow to the injured hind limb (Fig. $1 \mathrm{~A}$ ), reaching peak levels within $5 \mathrm{~min}$. Over the next 25 min, a slight decline in blood flow to a plateau phase was observed, though it remained significantly elevated throughout the 2-h observation period. Since neither systemic MAP (Fig. 1 $B$ ) nor systemic vascular resistance (Fig. $1 C$ ) were significantly altered by the scald, the increase in femoral blood flow ipsilateral to the injury reflected a decrease in hind limb vascular resistance (Fig. $1 D$ ). Finally, $\mathrm{Cl}$ increased slightly but insignificantly upon scald injury (Fig. 2). Mean PAP, PCWP, and pulmonary vascular resistance were unaltered by scalding (Table I).

In some animals (data not shown), an additional ultrasonic flow probe was placed around the ipsilateral dorsalis pedis ar-

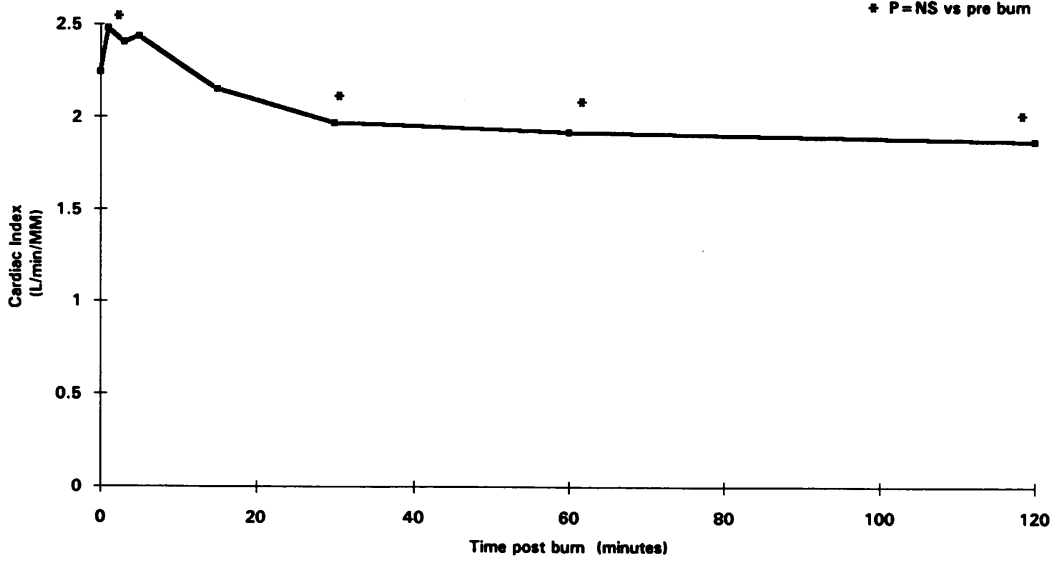

Figure 2. Time course depiction of cardiac index after scalding demonstrating no significant change over the period of observation. 
Table I. Characterization of Pulmonary Hemodynamic Parameter Alterations in Response to Scalding

\begin{tabular}{lrrr}
\hline \multicolumn{1}{c}{ Time } & Before burn & $\begin{array}{c}\text { After burn } \\
(5 \mathrm{~min})\end{array}$ & $\begin{array}{r}\text { After burn } \\
(60 \mathrm{~min})\end{array}$ \\
\hline CI (liter/min per $\left.\mathrm{m}^{2}\right)$ & $2.2 \pm 0.3$ & $2.5 \pm 0.2$ & $2.3 \pm 0.2$ \\
PAP (mmHg) & $13 \pm 0.5$ & $14 \pm 0.6$ & $14 \pm 0.6$ \\
PVR (mmHg/liter per $\mathrm{min})$ & $6.0 \pm 0.3$ & $5.6 \pm 0.3$ & $6.1 \pm 0.2$ \\
PCWP (mmHg) & $10 \pm 0.3$ & $11 \pm 0.5$ & $11 \pm 0.5$ \\
& & & \\
\hline
\end{tabular}

When compared to respective preburn values, there were no significant changes in mean PAP, PCWP, or pulmonary vascular resistance $(\mathrm{PVR}=\mathrm{PAP} / \mathrm{CO}) . P=\mathrm{NS}$ vs preburn.

tery, immediately proximal to the proposed site of scald. Baseline dorsalis pedis blood flows were approximately one fourth those of femoral blood flows. After scalding, dorsalis pedis blood flows increased dramatically when compared to baseline levels, and remained elevated throughout the observation period. In contrast to the injured side, the unburned hind limb showed no significant changes in blood flow or in vascular resistance.

Femoral artery blood flow, systemic MAP, and CI were monitored before scald in dogs pretreated with methysergide. This dose of methysergide was found to block the increased regional blood flow induced by intrafemoral arterial bolus injections of serotonin ( $10-100 \mu \mathrm{g} / \mathrm{kg}$ ), which itself produced no systemic hemodynamic effects. After femoral artery blood flow returned to baseline, methysergide $(0.1 \mathrm{mg} / \mathrm{kg})$ was administered by the peripheral intravenous route; no significant regional or systemic hemodynamic alterations occurred (Table II). However, the subsequent intrafemoral bolus injection of serotonin resulted in significant $(P<0.002)$ blunting of the hyperemic response to serotonin before methysergide $(65 \pm 10$ $\mathrm{ml} / \mathrm{min}$ increase in blood flow before methysergide; $10 \pm 3 \mathrm{ml} /$ min blood flow increase after methysergide).

In these same methysergide-treated dogs, scalding still caused an immediate, significant increase in femoral blood flow (Fig. $3 A$ ) and a decrease in regional vascular resistance (Fig. $3 \mathrm{~B}$ ). However, when compared to burn alone dogs, the regional hemodynamic alterations were significantly blunted.

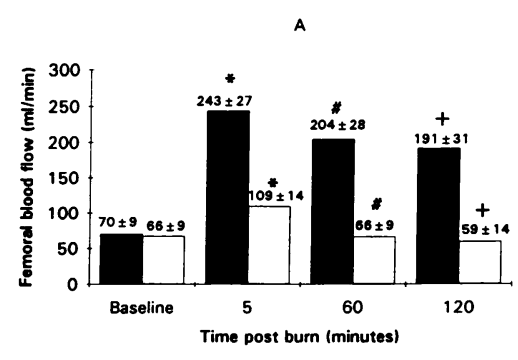

Figure 3. Comparison of femoral artery blood flow $(A)$ and resistance $(B)$ alterations between burn alone animals and animals treated with intravenous methysergide (MET) before injury. Note the blunting of the vasodilatory response in MET-treated animals, with a return to pre burn levels within

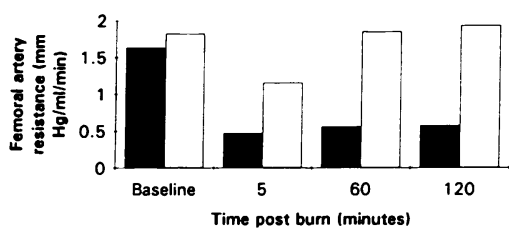

$60 \mathrm{~min}$ of scald injury. ${ }^{*} P<0.0005$ vs MET burn; ${ }^{*} P<0.02$ vs MET burn; ${ }^{+} P<0.04$ vs MET burn. $₫$, Burn only; $\square$, MET/burn.

Moreover, within $30 \mathrm{~min}$, femoral blood flow and vascular resistance had begun to return toward preinjury levels, reaching baseline levels by $60 \mathrm{~min}$. At all observation points, the values for each represent significant differences from burn only dogs.

To determine whether this agent could reverse the vasodilator response to scald, dogs were given methysergide intravenously $(0.1 \mathrm{mg} / \mathrm{kg}) 30 \mathrm{~min}$ after injury. Immediately thereafter, femoral blood flow decreased (Fig. $4 \mathrm{~A}$ ) and vascular resistance increased (Fig. $4 B$ ), each reaching preburn levels within $30 \mathrm{~min}$. Tenfold higher doses of methysergide had similar effects (data not shown).

To determine the selectivity of methysergide to inhibit femoral vasodilator responses mediated by serotonergic receptors, an additional group of experiments was performed, and data from these studies are presented in Table III. Femoral arterial bolus injections of serotonin $(0.001 \mu \mathrm{g} / \mathrm{kg})$, CATM (a seroto-

Table II. Scald-induced Hemodynamic Alterations in Animals Pretreated with Methysergide (MET) and Ritanserin (RIT)

\begin{tabular}{|c|c|c|c|c|c|}
\hline & \multicolumn{2}{|c|}{ Before Burn } & \multicolumn{3}{|c|}{ After Burn } \\
\hline & Before MET & After MET & $5 \mathrm{~min}$ & $60 \mathrm{~min}$ & $120 \mathrm{~min}$ \\
\hline Burned hind limb flow (ml/min) & $64 \pm 7$ & $61 \pm 8$ & $109 \pm 14^{*}$ & $66 \pm 9$ & $59 \pm 14$ \\
\hline Unburned hind limb flow $(\mathrm{ml} / \mathrm{min})$ & $58 \pm 11$ & $60 \pm 14$ & $59 \pm 14$ & $46 \pm 8$ & $45 \pm 14$ \\
\hline $\mathrm{MAP}(\mathrm{mmHg})$ & $125 \pm 4$ & $122 \pm 6$ & $128 \pm 5$ & $122 \pm 4$ & $114 \pm 4$ \\
\hline \multirow[t]{2}{*}{ CI (liter/min per $\left.\mathrm{m}^{2}\right)$} & $1.5 \pm 0.2$ & $1.5 \pm 0.2$ & $1.65 \pm 0.2$ & $1.66 \pm 0.2$ & $1.43 \pm 0.6$ \\
\hline & Before RIT & After RIT & $5 \mathrm{~min}$ & $60 \mathrm{~min}$ & $120 \mathrm{~min}$ \\
\hline Burned hind limb flow $(\mathrm{ml} / \mathrm{min})$ & $55 \pm 6.8$ & $57 \pm 7.3$ & $226 \pm 27^{*}$ & $199 \pm 16^{*}$ & $182 \pm 14^{*}$ \\
\hline Burned hind limb resistance $(\mathrm{mmHg} / \mathrm{ml}$ per $\mathrm{min})$ & 2.55 & 2.50 & 0.63 & 0.70 & 0.74 \\
\hline $\mathrm{MAP}(\mathrm{mmHg})$ & $140 \pm 14$ & $142 \pm 14$ & $142 \pm 14$ & $139 \pm 15$ & $135 \pm 13$ \\
\hline
\end{tabular}

Except as noted by *, scalding produced minimal alterations in regional blood flow when animals were pretreated with methysergide. On the contrary, pretreatment with ritanserin produced no changes in regional vasodilatory responses to scalding. ${ }^{*} P<0.0005$ vs preburn. 

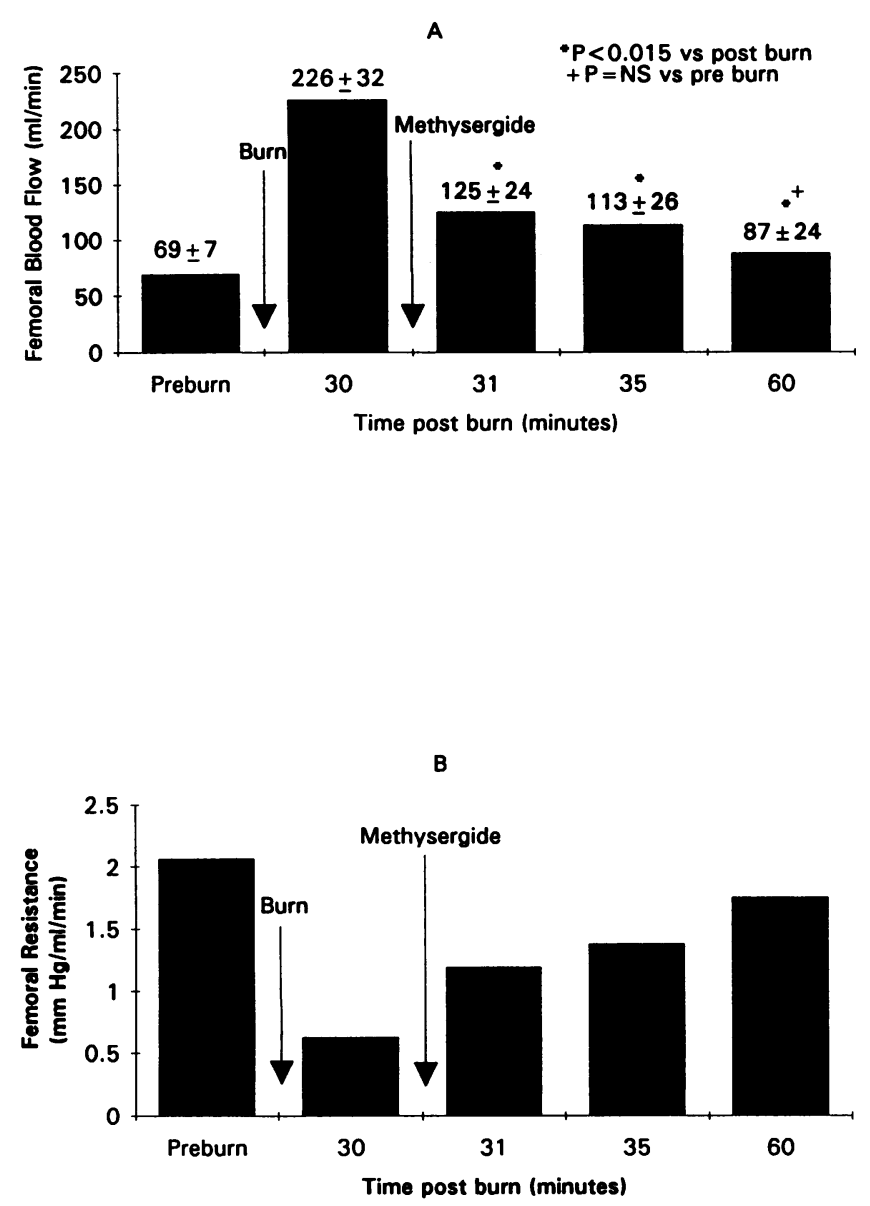

Figure 4. Effects of intravenous MET, given $30 \mathrm{~min}$ after the burn, on femoral blood flow $(A)$ and vascular resistance $(B)$ contrasted with the burn alone group. Within $1 \mathrm{~min}$ of MET injection, there was a significant decrease in the femoral vasodilatory response (and an increase in regional resistance), with a return to preburn values $30 \mathrm{~min}$ later.

$\operatorname{nin}_{1 \mathrm{~A}}$-like receptor agonist, $0.0001 \mu \mathrm{g} / \mathrm{kg}$ ), nitroglycerin (a direct activator of guanylate cyclase, $0.003 \mu \mathrm{g} / \mathrm{kg}$ ), and verapamil (a calcium channel blocking agent, $0.001 \mu \mathrm{g} / \mathrm{kg}$ ) all significantly increased femoral blood flow while methoxamine $(0.1 \mu \mathrm{g} / \mathrm{kg})$ significantly reduced femoral blood flow. Since none of these agents altered systemic mean arterial pressure, the increases in femoral blood flow produced by these agents directly reflect decreases in hind limb vascular resistance. 5 min after peripheral intravenous administration of methysergide $(0.1 \mathrm{mg} / \mathrm{kg})$, the hind limb vasodilator responses to serotonin and CATM were significantly decreased, whereas the hind limb vasodilator responses to nitroglycerin and verapamil were not significantly altered, nor was the hind limb vasoconstrictor response to methoxamine. These data suggest that methysergide selectively inhibited the hind limb vasodilator responses mediated by serotonergic , $_{1}$ receptors.

As methysergide readily crosses the blood brain barrier (10), serotoninergic receptors within the central nervous system (CNS) could have mediated the scald-induced alterations in regional hemodynamics. Therefore, the contribution of CNS receptors to this response was investigated in dogs given methysergide $(20 \mu \mathrm{g} / \mathrm{kg})$ into one common carotid artery before scalding. This dose was found to be the largest intracarotid
Table III. Mean Changes in Femoral Blood Flow after Intravenous Arterial Bolus Infusion of Known Vasodilator and Vasoconstrictor Substances before and after Peripheral Intravenous Infusion of MET

\begin{tabular}{ccc}
\hline Agent & $\begin{array}{c}\text { Percent }( \pm 1 \text { SE) increase } \\
\text { in femoral blood flow }\end{array}$ & $\begin{array}{c}\text { Percent }( \pm 1 \text { SE) increase } \\
\text { in MAP }\end{array}$ \\
\hline Serotonin $(n=5)$ & & \\
Before MET & $96 \pm 27$ & $-1.0 \pm 1.0$ \\
After MET & $7 \pm 1^{*}$ & $1.0 \pm 1.0$ \\
CATM $(n=5)$ & & \\
Before MET & $220 \pm 68$ & $1.4 \pm 1.0$ \\
After MET & $5 \pm 1^{*}$ & $0.0 \pm 0.0$ \\
Nitroglycerin $(n=5)$ & & $-0.2 \pm 0.2$ \\
Before MET & $252 \pm 81$ & $-0.8 \pm 1.3$ \\
After MET & $189 \pm 74$ & \\
Verapamil $(n=4)$ & & $-1.1 \pm 0.8$ \\
Before MET & $197 \pm 92$ & $-2.1 \pm 1.2$ \\
After MET & $139 \pm 45$ & $-0.2 \pm 0.2$ \\
Methoxamine $(n=4)$ & & $0.6 \pm 0.6$ \\
Before MET & $-37 \pm 9$ & \\
After MET & $-35 \pm 7$ & \\
\hline
\end{tabular}

In the absence of alterations in systemic mean arterial pressure, methysergide selectively blocked the vasodilator response to serotonin and CATM, but had no effect on the vasodilator response to nitroglycerin or verapamil, or on the vasoconstrictor response to methoxamine. ${ }^{*} P<0.01$ vs pre-MET.

dose that did not alter the hind limb vasodilator response to femoral artery injection of serotonin $(10-100 \mu \mathrm{g} / \mathrm{kg})$. Before scald, bolus intracarotid injection of methysergide did not significantly alter baseline systemic or regional hemodynamic measurements. In these same dogs, the characteristic femoral blood flow and vascular resistance responses to scald were not altered by the centrally administered methysergide ( Table IV). In contrast, the same dose of methysergide given preburn into the femoral artery of other dogs inhibited the femoral vasodilator response to scald (Fig. 5).

To further characterize the serotoninergic receptor subtype mediating these regional vasodilator responses, ritanserin $(0.1$ $\mathrm{mg} / \mathrm{kg}$ ), a serotonin ${ }_{2}$ receptor antagonist (11), was given intravenously to dogs before scald. This dose blocked the intrafemoral administration of the serotonin ${ }_{2}$ receptor agonist $(+)-1$ (2,5-dimethoxy-4-iodophenyl)-2-aminopropane hydrochloride $(10 \mu \mathrm{g} / \mathrm{kg})$ after intravenous ritanserin produced no

Table IV. Regional Blood Flow Response to Preburn Bolus Infusion of MET Directly into One Carotid Artery

\begin{tabular}{lcc}
\hline & $\begin{array}{c}\text { Burned hind limb } \\
\text { blood flow }\end{array}$ & MAP \\
\hline & $\mathrm{ml} / \mathrm{min}$ & $\mathrm{mmHg}$ \\
Baseline & $100 \pm 18$ & $155 \pm 9$ \\
Baseline/MET (central) & $110 \pm 10$ & $155 \pm 11$ \\
After Burn (5 min) & $357 \pm 57^{*}$ & $175 \pm 18$ \\
After Burn (60 min) & $260 \pm 21^{*}$ & $165 \pm 13$
\end{tabular}

Central administration of methysergide produced no alterations in the burn-induced regional vasodilatory response. ${ }^{*} P<0.04$ vs baseline. 


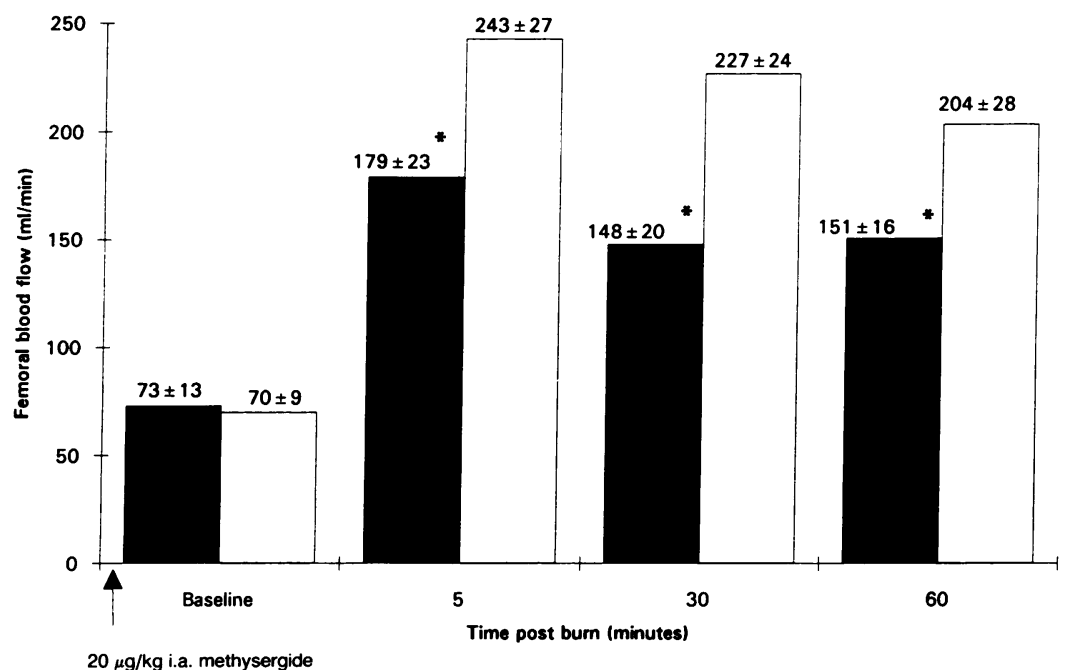

Figure 5. Alterations in femoral blood flow in animals pretreated with MET, injected into the femoral artery ipsilateral to the hind paw scalding. Compared to burn alone animals, MET administration resulted in significant modulation of the femoral vasodilatory response. $₫$, MET/burn; $\square$, burn only. effects on femoral blood flow or femoral vascular resistance. Preburn ritanserin injection had no effect on systemic or regional hemodynamic measurements at any observation point (Table II).

The contribution of other vasodilator mechanisms was investigated by administering one of the following blocking agents to groups of animals before scalding: atropine (muscarinic receptors), ICI 118551 ( $\beta_{2}$-adrenoceptors), BW

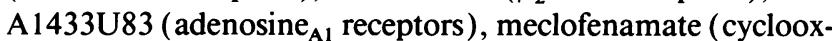
ygenase enzyme system), diphenhydramine (histaminergic receptors), and ranitidine (histaminergic $_{2}$ receptors). These agents were given in doses that blocked the femoral vasodilator responses to intrafemoral bolus injections of acetylcholine, isoproterenol, adenosine, arachidonic acid, and histamine, respectively (Table V). The antagonists did not alter baseline systemic MAP, CI, or hind limb blood flow, nor did they alter the hemodynamic response to scald (Table VI).

The contribution of endothelium-derived relaxing factor (EDRF) to this vasodilator response was assessed by giving LNAME $(100 \mathrm{mg} / \mathrm{kg})$, an inhibitor of nitric oxide synthase III (12). In unburned animals, administration of L-NAME before

Table V. Mean Increases in Regional Blood Flow after Intrafemoral Infusion of Agonist Agents Alone, and Intrafemoral Infusion of Agonist Agents after Peripheral Intravenous Injection of Blocking Agents

\begin{tabular}{lcc}
\hline \multicolumn{1}{c}{ Blocking agent/agonist } & $\begin{array}{c}\text { Mean }( \pm 1 \text { SE) } \\
\text { increase in } \\
\text { femoral blood } \\
\text { flow after } \\
\text { agonist }\end{array}$ & $\begin{array}{c}\text { Mean ( } \pm \text { 1 SE) increase in } \\
\text { femoral blood flow after } \\
\text { antagonist/agonist }\end{array}$ \\
\hline BW A1433U83/adenosine & $60 \pm 12$ & $15.5 \pm 4^{*}$ \\
Meclofenamate/arachidonic & $115 \pm 18$ & $23 \pm 6^{*}$ \\
$\quad$ Acid & $49.7 \pm 6$ & $11.8 \pm 3^{*}$ \\
ICI 118551/isoproterenol & $66 \pm 6$ & $21 \pm 4^{*}$ \\
Atropine/acetylcholine & $47 \pm 8$ & $14.3 \pm 3^{*}$ \\
Diphenhydramine/histamine & $99 \pm 4$ & $17 \pm 2^{*}$ \\
Ranitidine/histamine & & \\
\hline
\end{tabular}

In each instance, effective receptor blockade dosage was confirmed by the inability of each agonist to increase blood flow in the presence of a respective receptor blocking agent. ${ }^{*} P<0.05$ vs agonist. the burn increased systemic arterial pressure and hind limb vascular resistance, and decreased hind limb blood flow to steady state values during a 45-75 min observation period. However, the femoral vasodilator response to scalding was not altered by L-NAME (Table VII). The inducible form of nitric oxide synthase II (NOS II) was evaluated by preburn administration of 3-ATINE. The dose of 3-ATINE $(75 \mathrm{mg} / \mathrm{kg})$ has been shown in rat models to block the release of tumor necrosis factor and $\mathrm{N}_{2}$ intermediates, and to abolish the endotoxin-induced decrease in mean arterial pressure (13). 3-ATINE had no effect on baseline systemic or regional hemodynamics or on regional blood flow after scald injury.

The contribution of $\mathrm{K}_{\mathrm{ATP}}$ channels in mediating the regional vasodilatory response to scald was assessed with $U$ $37883 \mathrm{~A}$, a selective inhibitor of $\mathrm{K}_{\mathrm{ATP}}$ channels (14). In doses that selectively blocked the hind limb vasodilator response to cromakalim, an activator of $\mathrm{K}_{\mathrm{ATP}}$ channels, this dose did not affect the vasodilator response to isoproterenol or nitroglycerin (data not shown). Given before the burn, U 37883A had no effect on the hind limb vasodilator response to scald (Table VII).

\section{Discussion}

Data from this study demonstrate that in the absence of systemic or pulmonary hemodynamic changes, a small BSA burn in dogs results in a marked increase in blood flow to the site of injury concomitant with a decrease in vascular resistance. These results are consistent with studies that suggest the vasodilator response to a surface wound is primarily directed to that wound, not to uninjured tissues or adjacent "watershed" areas $(1,2,15)$.

This study was designed to limit the size and magnitude of the burn to the extent that there were no appreciable alterations in (a) systemic and pulmonary hemodynamic parameters and (b) blood flow and vascular resistance to skin/soft tissue remote from the burn site. Each of these goals was met throughout the experiments reported herein by standardizing the scald: $(a)$ the percent BSA injury was uniformly $<3 \%$ and $(b)$ a second degree burn was consistently produced, characterized by cutaneous hyperemia, skin blisters, and subcutaneous tissue swelling. Thus, in large measure, the direct impact of scald on regional hemodynamics was monitored. As such, data from this study are consistent with others that show a small BSA 
Table VI. Alterations in Regional and Systemic Hemodynamic Responses to Scald Injury in Animals Pretreated with Known Vasocative Blocking Agents

\begin{tabular}{|c|c|c|c|c|}
\hline Agent & Burned hind limb flow & Unburned hind limb flow & MAP & $\mathrm{CI}$ \\
\hline & $\mathrm{ml} / \mathrm{min}$ & $\mathrm{ml} / \mathrm{min}$ & $m m H g$ & liter/min per $\mathrm{m}^{2}$ \\
\hline \multicolumn{5}{|l|}{ Atropine } \\
\hline Baseline & $45 \pm 11$ & $44 \pm 12$ & $115 \pm 6$ & $2.0 \pm 0.4$ \\
\hline Baseline + blocker & $48 \pm 12$ & $45 \pm 12$ & $116 \pm 7$ & $2.2 \pm 0.3$ \\
\hline After burn $(5 \mathrm{~min})$ & $178 \pm 12$ & $41 \pm 6$ & $113 \pm 8$ & $2.6 \pm 0.4$ \\
\hline After burn $(60 \mathrm{~min})$ & $146 \pm 19$ & $36 \pm 6$ & $117 \pm 5$ & $2.3 \pm 0.3$ \\
\hline \multicolumn{5}{|l|}{ ICI 118551} \\
\hline Baseline & $44 \pm 11$ & $43 \pm 8$ & $115 \pm 7$ & $1.9 \pm 0.2$ \\
\hline Baseline + blocker & $46 \pm 10$ & $41 \pm 8$ & $114 \pm 5$ & $2.0 \pm 0.2$ \\
\hline After burn $(5 \mathrm{~min})$ & $200 \pm 17$ & $39 \pm 3$ & $111 \pm 7$ & $2.3 \pm 0.2$ \\
\hline After burn (60 min) & $151 \pm 23$ & $37 \pm 7$ & $117 \pm 5$ & $2.0 \pm 0.2$ \\
\hline \multicolumn{5}{|l|}{ BW A1433U83 } \\
\hline Baseline & $59 \pm 4$ & N/A & $115 \pm 1$ & $1.8 \pm 0.2$ \\
\hline Baseline + blocker & $54 \pm 9$ & N/A & $116 \pm 2$ & $1.9 \pm 0.2$ \\
\hline After burn ( $5 \mathrm{~min})$ & $192 \pm 33$ & N/A & $123 \pm 4$ & $1.6 \pm 0.2$ \\
\hline After burn $(60 \mathrm{~min})$ & $160 \pm 22$ & N/A & $122 \pm 3$ & $1.5 \pm 0.3$ \\
\hline \multicolumn{5}{|l|}{ Meclofenamate } \\
\hline Baseline & $36 \pm 9.6$ & $39 \pm 7$ & $124 \pm 7$ & $1.7 \pm 0.1$ \\
\hline Baseline + blocker & $37.5 \pm 11$ & $38 \pm 6$ & $120 \pm 7$ & $1.7 \pm 0.1$ \\
\hline After burn ( $5 \mathrm{~min})$ & $153 \pm 16$ & $48 \pm 9$ & $129 \pm 8$ & $1.7 \pm 0.1$ \\
\hline After burn (60 min) & $121 \pm 14$ & $28 \pm 6$ & $126 \pm 8$ & $1.5 \pm 0.2$ \\
\hline \multicolumn{5}{|l|}{ Diphenhydramine } \\
\hline Baseline & $81 \pm 26$ & $88 \pm 31$ & $150 \pm 14$ & N/A \\
\hline Baseline + blocker & $85 \pm 35$ & $81 \pm 28$ & $157 \pm 12$ & N/A \\
\hline After burn ( $5 \mathrm{~min})$ & $242 \pm 68$ & $114 \pm 58$ & $180 \pm 10$ & N/A \\
\hline After burn (60 min) & $205 \pm 30$ & $61 \pm 7$ & $165 \pm 11$ & N/A \\
\hline \multicolumn{5}{|l|}{ Ranitidine } \\
\hline Baseline & $75 \pm 2$ & N/A & $123 \pm 11$ & N/A \\
\hline Baseline + blocker & $86 \pm 3$ & N/A & $114 \pm 9$ & N/A \\
\hline After burn $(5 \mathrm{~min})$ & $279 \pm 14$ & N/A & $119 \pm 5$ & N/A \\
\hline After burn (60 min) & $266 \pm 15$ & N/A & $117 \pm 6$ & N/A \\
\hline \multicolumn{5}{|l|}{ Control burn } \\
\hline Baseline & $70 \pm 9$ & $65 \pm 9$ & $114 \pm 6$ & $2.3 \pm 0.3$ \\
\hline After burn $(5 \mathrm{~min})$ & $243 \pm 27$ & $77 \pm 17$ & $114 \pm 6$ & $2.5 \pm 0.2$ \\
\hline After burn (60 min) & $217 \pm 28$ & $53 \pm 12$ & $117 \pm 6$ & $2.3 \pm 0.2$ \\
\hline
\end{tabular}

The burn alone group is shown for comparative purposes. In each group, the injected blocking agent had no effect on the scald-induced regional vasodilatory response. $P=$ NS vs control burn group at each time interval.

scald increases blood flow for tissues involved in the burn, but does not alter pulmonary, systemic, or regional hemodynamics (5).

The marked hind limb vasodilator response to scald injury was significantly reduced by administering methysergide but not ritanserin before the burn, suggesting that serotonin -like $_{1}$ receptors play a major role in mediating this response. Since methysergide inhibited the hind limb vasodilator response to serotonin and CATM, but not to nitroglycerin or verapamil, the present data suggest that methysergide acted in a selective manner to antagonize serotonergic - $_{1}$-ike receptors. Although prostaglandins $(7,8)$ and $\beta_{2}$-adrenoceptors $(9)$ have been implicated as mediators of the increase in local blood flow, neither ICI 118551 nor meclofenamate altered the hind limb vasodilator response to burn, suggesting that neither $\beta_{2}$-adrenoceptors nor cyclooxygenase products appear to mediate this effect. Similarly, atropine, BW 1433U83, diphenhydramine, and ranitidine had no effect on the scald-induced increase in femoral blood flow, suggesting that this response is not mediated by muscarinic, adenosine $_{\mathrm{A} 1}$, histaminergic ${ }_{1}$, or histaminergic , $_{2}$-receptors.

The vasorelaxant response to serotonin in isolated conduit blood vessels has been shown to require an intact endothelial cell layer and to depend on formation of EDRF (16). Since pretreatment with L-NAME and 3-ATINE, respective inhibitors of NOS III-forming EDRF (12, 13, 16-19) and NOS II (20), did not alter the vasodilator response to scald, these data suggest that NO formed from the constitutive and inducible forms of NO synthase does not mediate this effect to a large degree. 
Table VII. Role of EDRF and $K_{A T P}$ Channels, Respectively, in Mediating Alterations in the Regional Vasodilatory Response to Scalding

\begin{tabular}{lcc}
\hline \multicolumn{1}{c}{ Agent } & $\begin{array}{c}\text { Burned hind limb } \\
\text { blood flow }\end{array}$ & MAP \\
\hline & $\mathrm{ml} / \mathrm{min}$ & $\mathrm{mmHg}$ \\
L-NAME & & \\
Baseline & $95 \pm 8$ & $117 \pm 7$ \\
Baseline + L-NAME (before burn) & $38 \pm 5^{*}$ & $154 \pm 12$ \\
After burn (5 min) & $179 \pm 19^{\ddagger}$ & $159 \pm 12$ \\
After burn (60 min) & $116 \pm 18^{\ddagger}$ & $152 \pm 10$ \\
3-ATINE & & \\
Baseline & $94 \pm 30$ & $145 \pm 16$ \\
Baseline + 3-ATINE (before burn) & $100 \pm 37$ & $150 \pm 14$ \\
After burn (5 min) & $321 \pm 59^{\ddagger}$ & $165 \pm 13$ \\
After burn (60 min) & $298 \pm 43^{\ddagger}$ & $145 \pm 10$ \\
U 37883A & & \\
Baseline & $69 \pm 8$ & $122 \pm 10$ \\
Baseline + cromakalim & $213 \pm 16^{* \ddagger}$ & $130 \pm 11$ \\
Baseline + cromakalim + & & \\
$\quad$ U 37883A (before burn) & $93 \pm 5$ & $115 \pm 5$ \\
After burn (5 min) & $192 \pm 15^{\ddagger}$ & $137 \pm 7$ \\
After burn (60 min) & $176 \pm 16^{\ddagger}$ & $112 \pm 9$ \\
& & \\
\hline
\end{tabular}

Of the blocking agents tested, none altered scald-induced regional vasodilatory response to injury. ${ }^{*} P<0.02$ vs baseline. ${ }^{\ddagger} P<0.02$ vs pre-burn.

Recently, $\mathrm{K}_{\mathrm{ATP}}$ channels have been identified in skeletal muscle and arterial smooth muscle (14). The possibility that this vasodilator response may be mediated by activation of these channels is unlikely, since U 37883A, an inhibitor of $\mathrm{K}_{\mathrm{ATP}}$ channels, had no effect on the hind limb vasodilator response to burn injury.

Since methysergide crosses the blood brain barrier (11), the hypothesis that serotonin receptors within the CNS mediate the femoral vasodilator response to scald was tested. Intracarotid arterial injection of methysergide did not alter the hind limb vasodilator response to scald or to femoral artery injection of serotonin. In contrast, the same methysergide dose given directly into the femoral vascular bed inhibited the hind limb vasodilator response to scald and to femoral artery injection of

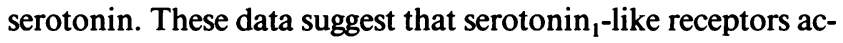
tivated locally, not centrally, mediate the hind limb vasodilator response to scald.

Since pretreatment with methysergide prevented the hind limb vasodilator response to scald, serotoninergic receptors contribute in large measure to this effect. Moreover, this response to scald was rapidly reversed by administration of methysergide after the burn. These data suggest that persistent activation of serotonin ${ }_{1}$-like receptors mediates the prolonged increase in hind limb blood flow after scald. Although mediation of this response may be species dependent, the present study is unique by providing evidence that a specific vasodilator mecha-

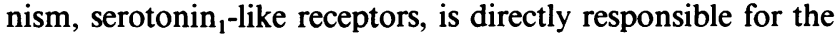
sustained vasodilator response to local thermal injury. Since methysergide given either into the femoral artery $(20 \mu \mathrm{g} / \mathrm{kg})$ or intravenously $(100 \mu \mathrm{g} / \mathrm{kg}$ ) produced rapid inhibition of other- wise augmented femoral blood flow, the local hemodynamic response to a small scald appears reversible. However, an early ( 5 min after burn ) component of the response is methysergide insensitive, and the mediation of this effect remains unknown.

A marked continuous increase in serotonin release into the systemic circulation does not appear to mediate the continuous activation of serotonin ${ }_{1}$-like receptors, since infusions of serotonin directly into the femoral vascular bed, in doses necessary to produce femoral blood flow increases similar to those after scald, caused marked changes in systemic hemodynamics. This effect was not observed with the small BSA scald used herein. Furthermore, platelet counts remained unchanged throughout the experiments, suggesting that serotonin release from platelet destruction or aggregation cannot account for the persistent activation of serotonin $n_{1}$-like receptors in the hind limb vascular bed after scald.

Locally released serotonin, via an alteration in its local removal or via increased sensitivity of serotonin $_{1}$-like receptors, may be responsible for the hind limb vasodilator response to scald. Others have demonstrated that in a septic hind limb model, effluent from the infected leg dilated other regional vascular beds (21). However, Aulick et al. have suggested that noninfectious forms of limited tissue injury do not release significant quantities of vasodilator substances ( 3 ). Thus, the present data are in agreement with the concept that the type of pathological insult inducing local vasodilation may determine the extent to which other vascular beds are subject to hemodynamic alterations. In this regard, the small BSA burn injury used in this study could have explained the inability of the injury to induce a humorally mediated response in other vascular beds.

In conclusion, a small BSA burn to the hind leg in dogs produces marked, selective, and prolonged hind limb vasodilation. This vasodilator response is predominantly mediated by

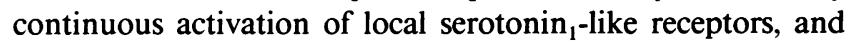
does not depend in large measure on a variety of other diverse vasodilator mechanisms.

\section{References}

1. Aulick, L. H., D. W. Wilmore, A. D. Mason, and B. A. Pruitt. 1977. Influence of the burn wound on peripheral circulation in thermally injured patients. Am. J. Physiol. 233:H520-H526.

2. Wilmore, D. W., L. H. Aulick, A. D. Mason, and B. A. Pruitt. 1977. Influence of the burn wound on local and systemic responses to injury. Ann. Surg. 186:444-458.

3. Aulick, L. H., W. B. Baze, C. G. McLeod, and D. W. Wilmore. 1980. Control of blood flow in a large surface wound. Ann. Surg. 191:249-258.

4. Ferguson, J. L., G. F. Merrill, H. I. Miller, and J. J. Spitzer. 1977. Regional blood flow distribution during early burn shock in the guinea pig. 1977. Circ. Shock. 4:317-326.

5. Owen, D. A., and H. E. Farrington. 1976. Inflammation and the vascular changes due to thermal injury in the rat hind paws. Agents Actions. 6:622-626.

6. Turinsky, J., I. H. Chaudry, D. J. Loegering, and K. M. Nelson. 1981. Local effect of thermal injury on skeletal muscle blood flow and nucleotide levels. Circ. Shock. 8:31-40.

7. Proctor, K. G., S. Shatkin, P. M. Kaminiski, J. R. Falck, and J. H. Capdevila. 1988. Modulation of arteriolar blood flow by inhibitors of arachidonic acid oxidation after thermal injury: possible role for a novel class of vasodilator metabolites. Circulation. 77:1185-1196.

8. Alexander, F., M. Mathieson, K. H. T. Teoh, W. V. Huval, S. Leluk, R. Valeri, D. Sherpo, and H. B. Hechtman. 1984. Arachidonic acid metabolites mediate early burn edema. J. Trauma. 24:709-712.

9. Gore, D. C., D. Honeycutt, F. Jahoor, R. Barrow, R. Wolfe, and D. N. Herndon. 1991. Propranolol diminishes extremity blood flow in burned patients. Ann. Surg. 213:568-574. 
10. Nelson, R. F. 1973. A new prophylactic agent for migraine-four year's experience in seventy-five patients. Headache. 13:96-103.

11. Korstanje, C., R. Sprenkles, H. N. Doods, J. G. Hugenburgh, E. Boddeke, H. D. Batnik, M. J. C. Thoolen, and P. A. Van Zwieten. 1986. Characterization of fluprofylline, ritanserin, butanserin, and R 56413 with respect to in vivo $\alpha_{1}, \alpha_{2}$, and 5-HT ${ }_{2}$ receptor antagonism and in vivo affinity for $\alpha_{1}, \alpha_{2}$, and 5-HT receptors: comparison with ketanserin. J. Pharm. Pharmacol. 38:374-379.

12. Förstermann, U., J. S. Pollack, H. H. H. W. Schmidt, M. Heller, and F. Murad. 1991. Calmodulin-dependent endothelium-derived relaxing factor/nitric oxide synthase activity is present in the particulate and cytosolic fractions of bovine aortic endothelial cells. Proc. Natl. Acad. Sci. USA. 88:1788-1792.

13. Leblanc, R., J. Xie, A. Warner, J. Kolls, J. Shellito, T. Malinski, W. R Summer, and S. Greenberg. 1992. Nitric oxide derived from macrophages rather than neutrophils mediates endotoxin-induced hypotension. Clin. Res. 40:777A

14. Cipkur-Dubray, L., M. Swirtz, S. Kahn, S. Humphrey, L. Skaletzky, and K. Meisheri. 1992. U-37883A: A structurally novel antagonist of the vascular $\mathrm{K}_{\mathrm{ATP}}$ openers. FASEB (Fed. Am. Soc. Exp. Biol.) J. 6:A1777-A1778.

15. Gump, F. E., J. B. Price, and J. M. Kinney. 1970. Blood flow and oxygen consumption in patients with severe burns. Surg. Gynecol. \& Obstet. 130:23-28.
16. Chyu, K. Y., P. H. Guth, and G. Ross. 1991. Effect of $N$-nitro-L-arginine methyl ester on arterial pressure and on vasodilator and vasoconstrictor responses: influence of initial vascular tone. Eur. J. Pharmacol. 212:159-164.

17. Fineman, J. R., M. A. Heymann, and S. J. Soifer. 1991. N-nitro-L-arginine attenuates endothelium-dependent pulmonary vasodilatation in lambs. $\mathrm{Am}$. J. Physiol. 260:H1299-H1306.

18. Gardiner, S. M., A. M. Compton, P. A. Kemp, and T. Bennett. 1990. Regional and cardiac hemodynamic responses to glyceryl trinitrate, acetylcholine, bradykinin, and endothelin- 1 in conscious rats: effects of $N$-nitro-L-arginine methyl ester. Br. J. Pharmacol. 101:632-639.

19. Giles, H., M. L. Bolofo, and G. R. Martin. Agonist-and tissue dependence of susceptibility of endothelium-dependent relaxations of L-NAME. Br. J. Pharmacol. 100:452P.

20. Rouiller-Buchmuller, Y., P. Schneider, S. Corradin-Betz, J. Smith, and J. Mauel. 1992. 3-Amino-1,2,4-triazole inhibits macrophage NO synthase. Biochem. Biophys. Res. Commun. 183(1):150-155.

21. Hemereck, A. S., and A. P. Thal. 1969. Mechanisms for the high circulatory requirements in sepsis and septic shock. Ann. Surg. 170:677. 